\title{
Faculty Studies: A Survey of Their Use in Selected Libraries
}

A mail survey was made of faculty study use in selected academic libraries. An examination of reported faculty to faculty study ratio suggests that no single mathematical formula can be employed when determining local needs. Other factors influencing the demand for faculty studies are examined. The management of faculty studies through a properly administered policy statement can help to control space shortages and reduce irregularities common to most libraries providing faculty studies.

$\mathrm{U}$ NIVERSITY and college libraries are seldom planned and built without faculty studies. Faculty studies absorb considerable library space and are the cause of housekeeping difficulties in all libraries. Library literature lacks adequate information; there is no accepted doctrine on the subject.

The purpose of this survey is to review the current trend of faculty use of library studies as well as to probe selected institutional policies, problems, and attitudes on this matter. The thirtytwo libraries selected for the survey are relatively new, having been built within the past few years. The institutions employ an average of 898 faculty members and have an average of fourteen hundred student seats available in the libraries. The smallest institution reports three hundred full-time faculty members; the largest, twenty-seven hundred.

All institutions participating in the survey are basically urban universities.

The only feasible way to conduct the

$M r$. Spyers-Duran is Director of Libraries, Western Michigan University. This study was made while he was Assistant Director of Libraries, University of Wisconsin-Milwaukee. survey economically was through mail. A self-administered questionnaire was developed and mailed to thirty-two institutions. There were thirty-two respondents, of which twenty-four provided complete information. The remaining eight supplied partial information or none at all beyond the fact that their libraries possess no faculty studies.

The questionnaire defined the faculty study as "a small enclosed area for individual study; not an open study station." The definition seemed necessary in view of the fact that there is no standard definition agreed upon in this matter. In one institution a faculty carrel may mean an open study desk, in another institution it may mean an enclosed cubicle or study room. Library building planning guides are of little help in clarifying the issue. Burchard distinguishes between studies and carrels by saying that as a rule a "carrel" is smaller than a "study" and that "carrels" are for graduate students while faculty use "studies."1 Wilson and Tauber ${ }^{2}$ and Met-

\footnotetext{
1 J. E. Burchard, Planning the University Library Building (Princeton: Princeton University Press, 1949), p. 46.

${ }^{2}$ L. R. Wilson and Maurice F. Tauber, The University Library; Its Organization, Administration and Functions (New York: Columbia University Press, 1956), p. 499.
} 
calf: use the word "carrel" for enclosed faculty studies in their respective works. The definition of the faculty study or carrel on the survey questionnaire kept the confusion to a minimum. The answers which some institutions related to open-study stations have been omitted here.

\section{How Many Studies Should a Library Have For Faculty Use?}

The questionnaires returned reveal that 65 percent of the libraries have faculty studies. An additional 6 percent indicate plans to add such faculty studies as building expansion permits.

Just how many studies a library should provide to satisfy demand is not an easy question to answer.

Eighty-two per cent of the libraries with faculty studies indicate that the demand, at least on the surface, is greater than the supply (see Table 1). Eighteen per cent of the libraries which indicate an "adequate" number of faculty study facilities are listed in Table 2.

The faculty-to-study ratio in Table 2 ranges from 1.6:1 to $31: 1$. Since one group reports these ratios to be adequate, one may wonder why sixty per cent of the libraries in Table 1 do not consider their facilities adequate. It will be noted that Table 1 shows ratios ranging from $4: 1$ to a low of $337: 1$.

An examination of these facts suggests that no single mathematical formula will provide the answer to every library need. Let us examine some of the factors which could influence the demand for faculty studies in an institution.

1. It appears to the surveyor that in institutions where teaching is emphasized rather than research there is less demand for faculty studies.

2. Libraries with extremely attractive facilities attract a greater percentage

${ }^{3}$ Keyes D. Metcalf, Planning Academic and Research Library Buildings (New York: McGraw-Hill, 1956), p. 101-103. of faculty who want facilities separate from students. ${ }^{4}$

3. Universities with full-scale Ph.D. programs demand more faculty study facilities than those institutions which level off at Masters programs or have a limited number of Ph.D. programs. Additional factors, minor as they may seem, may also increase the shortage of faculty studies in certain situations.

1. The shortage of faculty studies is sometimes because professors obtain the privilege of using the facility, then do not make proper use of it. At times faculty stop using the facility altogether and do not inform the library. For instance, faculty assigned a study leave for an extensive trip, or terminate employment without reporting to the library. Shortage of faculty studies may result when a number of professors obtain faculty studies, then sublet them to their students. This may happen in institutions where graduate students actually have their own study facilities.

2. In spite of the claimed shortage of

4 Ralph Ellsworth, Planning the College and University Library Building ([Boulder, Colo.]: 1960), p. 74 .

TABLE 1. Ratio of Faculty to

Faculty Studies in Institutions Where the Number of Faculty Studies Are Reported "Inadequate"

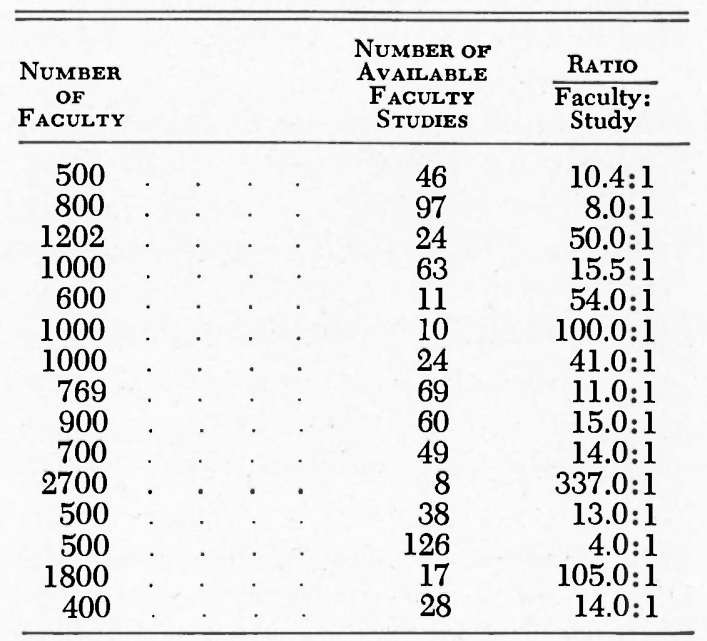


TABLE 2. Ratio of Faculty to

Faculty Studies in Institutions Where the Number of Faculty Studies Are Reported "Adequate"

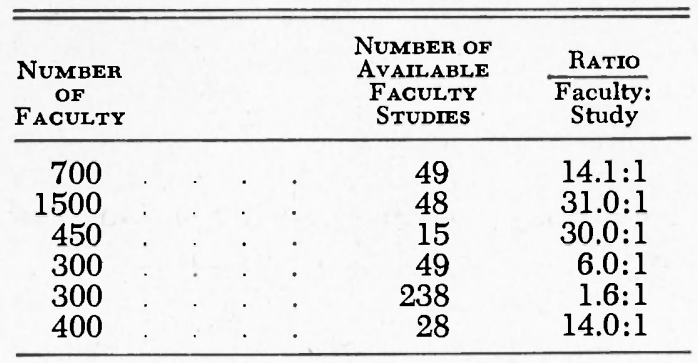

faculty studies, libraries assign them to other than faculty. Twenty per cent of the libraries indicate it is their policy to include visiting scholars for study privileges. Thirty-three per cent of the libraries consider graduate students if they show an adequate cause. Fifteen per cent of the libraries indicate they give consideration to ministers, state officials, and other dignitaries if the occasion arises.

3. Most libraries consider faculty members uncooperative in observing regulations in respect to faculty studies. Yet only fifty per cent of the libraries indicate they have a written policy statement available for use and distribution to faculty. The obvious lack of instructions to faculty may be an important factor contributing to study shortage in some institutions.

4. Libraries tend to assign faculty studies to coincide with a semester, quarter, academic year, or even with a calendar year. While these may seem convenient target dates to set, they are actually irrelevant to the actual needs of a scholar. Libraries assigning studies on an academic calendar basis may tie up facilities after the faculty members are through with their use. Libraries aiming at a better use of such facilities might attempt to determine the approximate length of intended use through an interview with the faculty member. Logical as this method may seem, only 10 per cent of the institutions report they practice such control.

The shortage of faculty studies is not the only problem they pose. There are other housekeeping matters which are sometimes delicate issues in academic circles.

One of the major problems reported is the search for uncharged material kept in studies. All libraries report they check faculty studies regularly and remove uncharged material. This may be irritating to some faculty members. Recognizing the public relations value of not removing uncharged material from faculty studies, one institution uses stack pages to prepare the charge records when necessary. The frequency of faculty study checks varies a great deal from institution to institution. The most popular practice is to check irregularly but at least once a week. Only 15 per cent of the libraries report daily or every-otherday checks.

Few libraries have established special lending rules for faculty studies. Sixtysix per cent do not use separate circulation policies. Those which do indicate a greater flexibility by granting liberal loan periods or by circulating material which would normally not be allowed to be taken outside the building.

Noise must be considered when establishing policies concerning use of typewriters in studies. Ninety per cent of the libraries indicate typing is permitted in faculty studies. Ten per cent restrict typing to certain studies designed to absorb typewriter noise.

None of the libraries permit the use of studies as office space. This may be one of the reasons no faculty study is equipped with a telephone. The lack of telephones is also a feature preferred by researchers who want to get away from interruptions when using the library. Sixty per cent of the libraries will not "page" a faculty member out of re- 
spect to his sanctuary and for other practical reasons.

Smoking is permitted in faculty studies by 71 per cent of the libraries. Others indicate that while they have smoking restrictions faculty smoke as long as they have the privacy of an enclosed study. None of the libraries permit eating or drinking in faculty studies. Yet 80 per cent report housekeeping problems along these lines.

Nobody seems to have the magic solution to all the housekeeping problems. Regular inspection of studies and personal contact between faculty and library staffs can help to control irregularities. Personal contact is maintained conveniently when keys to the individual faculty studies must be picked up and deposited at a central location such as the circulation or reserve desk each time the faculty member uses the facility. A few libraries use such times of personal contact to point out a few "do's" and "don'ts." The system might also be used to measure the extent of use of the studies and will help identify those who have signed up for a study but are not using it. Further, this system may create controllable conditions to detect whether or not the study is used for the purpose for which it was originally assigned.

All libraries indicate that they cope with the problem of faculty studies by enlisting the aid and advice of their respective library committees. However convenient this method may seem, it does not eliminate the total problem.

Would librarians eliminate faculty studies from their buildings if possible? Surprisingly, only 20 per cent said yes. The minority group prefers unreserved open carrels instead of enclosed studies for faculty for the following reasons: 1. It is impossible in most libraries to provide an enclosed study for each faculty member.

2. Proprietary sense develops by holder, resulting in abuse and unhappiness if privilege is rescinded.
3. Other faculty is often dissatisfied when no space is available.

4. Where building budgets are limited, a choice must be made between faculty studies and other essential functions. The surveyor constructed a model policy statement regarding faculty studies, based on the answers and material provided by cooperating libraries. This model policy may be useful in full or in part to those needing to establish new policies or practices as well as for revising or adjusting existing ones. The statement covers the following areas:

1. Criteria for assignment.

2. Regulations for use.

3. Procedure for charging material used.

4. Loan period.

Policy Statement for the Use and Assignment of Faculty Studies

\section{A. Policy for the Assignment of Faculty Studies}

1. All members of the University faculty and instructors who are not candidates for advanced degrees are eligible for Faculty Studies.

2. Studies will be assigned for specific research projects that require library materials which cannot, or can only with difficulty, be used away from the library; and for projects requiring facilities for uninterrupted study or writing.

3. Studies will be assigned by the Director and/or Assistant Director of Libraries to members of the faculty who are engaged in:

a) Writing a book or research paper.

b) Preparation of course syllabus.

c) Performance of a committee function requiring extended use of library materials.

4. Applications for Studies will be made in writing to the Director of $\mathrm{Li}$ braries. Application forms will be made available at the office of the Director. In case of over-subscription of Studies, the Faculty Library Committee will determine priority. 
5. Studies will be assigned for specific projects, but not to exceed one semester. Applications for shorter periods, a summer, or even a period of a few weeks will be in order.

6. A Study holder may apply for renewal at the end of his assigned period, but he will have no priority over other applicants.

7. Studies will be for research and scholarship only and will not provide office or conference space as such. Visiting will be discouraged.

8. Insofar as possible, faculty members will be assigned Studies near the books they intend to use.

9. Faculty members may not sublease Studies assigned to them.

10. If agreeable to all parties concerned, double or multiple assignments to a single Study may be made.

11. It is the responsibility of the faculty member to notify the Librarian's office when the Study assigned to him is no longer needed.

B. Regulations for the Use of Faculty Studies

1. Studies have been furnished and equipped for faculty use. No furniture is to be moved from or introduced into them, except by arrangement with the Director's office.

2. Faculty Study keys may be picked up from the Circulation Desk. Keys should be returned there before leaving the library building.

3. Walls and doors must be kept free of nails, tape or any other methods of affixing objects.

4. Occupants are urged, out of deference to colleagues, to avoid disturbances caused by visiting in the individual Studies.

5. Faculty Studies should be kept neat and orderly. Smoking, food, and beverages are prohibited.

6. Damage to any furniture or equipment and necessary repairs or replacements should be reported immediately to the Director's office.

7. Study holders are responsible for the observance of all regulations. The library reserves the right to revoke assignments or stack privileges at its discretion.

\section{Charging Procedures for Faculty with Assigned Study Areas}

1. Library materials may be charged out for: a) Home or office use, or b) Faculty Study use.

2. Any faculty member planning to use an item in a Faculty Study for over two hours must charge it out at the Circulation Desk.

3. Materials charged to "Faculty Study" are not to be removed from the building.

4. Circulation Desk attendants will insert a specific checkout slip in books to be used in the Faculty Study. This slip should be kept in place so that the words "In Use" show clearly above the top of the book; on termination of use, the card must be inverted to show "To Be Discharged" and returned to the Circulation Desk for discharging.

5. All materials charged out to the Faculty Studies must be returned to the Circulation Desk for discharging.

6. When signing for materials for Faculty Studies, assigned room numbers must be included as follows:

John Doe

Lib 404

7. All library materials which are not charged out and do not have the "In Use" slip inserted in the manner described above, will be picked up by library personnel daily.

\section{Loan Periods for Faculty Studies}

1. To provide equal access and balanced distribution of materials available in the library to all University personnel, the Faculty library committee establishes the following loan periods for material used in Faculty Studies.

a) Books: One month. When a book is directly related to a research project, a faculty member may request a semester loan.

b) Periodicals: Three days. Exceptions are current periodicals in great demand which do not circulate.

c) Reference Books, Bibliographies, Indexes: These items do not cir- 
culate and must be used in the Reference Department.

d) Documents: Seven days.

\section{Conclusion}

It seems that in most academic libraries some problems are encountered in the management of faculty studies. In general, library staffs consider them a nuisance, in a sense wishing they did not exist. Recognizing the useful aspects of the facility, few administrators would eliminate faculty studies from their buildings. It appears that the majority of problems in faculty study room management cited by librarians are actually minor in a broad sense of total library operations. The fact that minor problems can be irritating to some inflates the actual size of the issues. It has been suggested that better communications between users of faculty studies and library staff is needed to improve conditions of working relationship.

The reported shortage of faculty studies may be helped in some situations through establishing firm, realistic policy statements. It is equally important that library staff responsible for implementation of policy statements recognize the need for sound management practices.

The model policy and procedure was designed as a reflection of what the surveyor considers the best features in current faculty study management in leading academic institutions. This statement should be looked at as a blueprint for ideas which is to be examined and evaluated from a local point of view. If properly applied, it can be helpful in solving many of the needs of all concerned.

\section{APPENDIX I}

\section{Faculty Carrel Use Study}

1. Does the main library of your campus provide individual faculty carrels? YES .... NO

- A small enclosed area for individual study; not an open study station.
2. If yes, please state their number:

3. Are the number of carrels available adequate for this group? YES .... NO .....

4. Approximately how many faculty are served by your library?

5. How many student seats do you have in your library?

6. Do you have a written policy statement on the distribution and use of these faculty carrels? YES .... NO ...

(If yes, please attach a copy to reply).

7. Do you have a library faculty advisory committee? YES

NO

8. Did this committee help you to establish a carrel use policy? YES NO .....

9. Do you have written instructions to the occupants of these carrels? YES

NO .... (If yes, please attach a copy to reply).

10. Do you permit the use of faculty carrels for office use? YES .... NO .....

11. Do you permit smoking in the carrel? YES ... NO

12. Do you permit eating and drinking in the carrel? YES .... NO

13. Do you permit typing in the carrel? YES .... NO ....

14. Have you installed telephones in any of your carrels? YES NO .....

15. Will you "page" a carrel using faculty member if an outside call comes in? YES .... NO

16. What are the typical housekeeping problems you consider most serious?

17. What measures have you taken to ease those problems?

19. What is the typical length of time a carrel is assigned to an individual?

20. If you would redesign your library would you eliminate individual carrels for faculty? YES .... NO ....

21. If yes, please present a brief argument.

22. Do you have a separate set of circulation policies for carrel users? YES NO .... (If yes, please attach).

23. Do you charge out to carrels:

A. Current periodicals YES

B. Reference books YES NO 
C. Books from stacks YES

NO

24. Does your staff check these carrels for material which was not charged out? YES .... NO .....

25. If yes, how frequently: Weekly Monthly .... Irregularly

26. Do you assign carrels to non-faculty? YES .... NO

27. If yes, to whom?

28. If you feel that I have overlooked any pertinent information please add:
29. $\square$ Please send me a copy of the survey when completed:

Name

Title

Address

30. Please complete and return questionnaire at your earliest convenience but not later than January 4, 1967. Thank you.

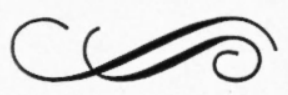

